\title{
EXPERIMENTAL STUDY OF THE EFFECTS OF FLOW DISCHARGE, DIAMETER, AND DEPTH ON SHEAR STRESS IN A RECTANGULAR CHANNEL WITH RIGID UNSUBMERGED VEGETATION
}

\author{
MATURI Foad ${ }^{\text {a }}$, BEHDARVANDI ASKAR Mehdi ${ }^{\text {a* }}$ \\ ${ }^{\text {a }}$ Department of Offshore Structures, Faculty of Marine Engineering, Khorramshahr University of Marine Science and \\ Technology, Iran, e-mail: * sazehenteghal@yahoo.com
}

Received: 15.12.2018 / Accepted: 16.02.2019 / Revised: 20.08.2019 / Available online: 10.12.2019

DOI: 10.2478/jaes-2019-0021

KEY WORDS: Vegetation, Rectangular channel, Shear stress, Physical model, Knife edge flume, Load cell.

\begin{abstract}
:
Shear stress is one of the most critical parameters in hydraulic and coastal engineering, which is often measured indirectly. Since there is no instrument to measure this parameter directly and given that it is usually calculated by measuring other parameters such as velocity and pressure and using some equations, shear stress measurement is often accompanied with large measurement errors. In this study, a new technique and direct measurement using physical modeling in a hydraulic knife-edge flume and load cell were employed to measure the shear stress in a rectangular channel with rigid unsubmerged vegetation with $D_{v}=20,25$, and $32 \mathrm{~mm}$ in $T_{0}$ $\mathrm{Q}=25$ and $30 \mathrm{Lit} / \mathrm{S}$ and $\mathrm{y}=10,12,17$, and $20 \mathrm{~cm}$. The results indicate that the shear stress and the dimensionless $\bar{\tau}$ ratio decrease in a constant flow discharge with increasing the flow depth. It was also shown that the shear stress would be enhanced with an increase in vegetation diameter due to increasing vegetation density against flow. According to dimensionless ratios of $\frac{\tau_{0}}{\tau}$ and $\frac{D_{y}}{y}$ in the graphs and considering the trend lines with appropriate correlation coefficients, some equations were presented to calculate the shear stress in the concerned range.
\end{abstract}

\section{INTRODUCTION}

Shear stress on the floor and walls have implications in many important hydraulic equations and sediment transport such as calculations of suspended load and bed-load transport, estimation of channel designs and stable rivers, selection of suitable drainage basins, designs for wall erosion control structures and so on. It is also necessary to know the distribution of shear stress across the rivers to predict crosssectional geometry changes, especially the ones resulting from flood passage. In this case, the use of the general formula for the shear stress on the river floor, which calculates the average shear stress with an assumption of uniform flow, is not practical (Hoshmandi F., Zahiri, 2014).

Measuring and calculating shear stress in hydraulic engineering can be considered as one of the key activities having always been of interest to researchers and experts in this field. In this regard, the present study aimed to describe the direct measurement method in open channels using a special type of laboratory hydraulic flume, called knife-edge flume modeling for rigid unsubmerged vegetation. Shear stress was measured directly using the features of this flume by load cell. The experiments in this study were developed and conducted by the research authors in Khuzestan Province Water Resources Management Laboratory Center affiliated to Khuzestan Province Water and Power Organization.

A lot of studies have been carried out to determine the amount and distribution of shear stress in open channels. According to these studies, several factors such as gravity, secondary flow patterns, geometric shape of the channel section, ratios of dimensions, velocity distribution, roughness of bed and walls and the distribution of roughness in the channel have impacts on the distribution of stress in the channel. According to some studies, although secondary flows have a velocity up to $2 \%$ of the main flow velocity, they play a significant role in distributing shear stress in the channel (Nezu, and $\mathrm{H}$. Nakagawa, 1993). Knight et al. conducted their studies on a smooth rectangular channels on the basis of laboratory results and proposed experimental equations for the distribution of boundary shear stress, based on which the average shear stress in the bed and wall can be calculated with an appropriate approximation (D. W. Knight, J. D. Demetrious, 1984).

\footnotetext{
* Corresponding author: Mehdi Behdarvandi ASKAR, e-mail: sazehenteghal@yahoo.com
} 
Tominaga et al. also studied shear stress and secondary flows in a smooth and rough rectangular and trapezoidal channel. Using velocity distribution rate and its relationship with shear velocity, they developed Equation (1) to calculate shear stress. They presented their results as diagrams of stress distribution on the bed and wall.

$$
\tau_{0}=\rho u
$$

where: $\tau_{0}$ is stress on the channel bed, $\rho$ is fluid den: 155 $u$ - represents shear velocity (A. Tominaga, 1989).

Dey and Lambert annually examined the shear stress in open channels with impermanent and non-uniform flows, and presented equations to calculate shear stress in these types of flows (S. Dey, and M. F. Lambert, 2005). Guo and Julien offered a numerical solution to estimate the shear stress distribution on the floor and walls of a smooth rectangular channel, assuming a constant viscosity of whirlpools regardless of the secondary flows. According to the comparisons with laboratory findings, the calculated shear stress values were about $17 \%$ less than the shear stress on the walls. This error was reduced by $6 \%$ by adding two modification parameters (J. Guo, and P. Y. Julien, 2005). Zarrati et al. examined this issue by a semi-analytic model using a simplified flow velocity equation and provided acceptable results compared to laboratory results (A. R Zarrati., Y. C. Jin, and S. Karimpour, 2008).

Shear stress measurement methods can be classified into two direct (Winterer, 1977; Frenwells et al., 1996) and indirect (Chow, 1959; Preston, 1954; Porter et al., 2000; and Buckler et al., 2008) categories. Among different shear stress measurement methods, the Preston tube can be considered as the most common one. The shear stress calculated by this method and the relevant equations can be used to calculate the apparent shear stress or the transition movement (Behdarvandi Askar M., Fathi Moghadam M. and Mosavi Jahromi S. H., 2013).

\section{MATERIALS AND METHODS}

All experiments in this study were carried out in a hydraulic knife edge flume with a $15-\mathrm{m}$ length, a $1.07-\mathrm{m}$ width, and a $10^{-4}$ bed slope. To provide the water flow in this channel, a pump with a flow rate of $1600 \mathrm{Lit} / \mathrm{min}$ and two reservoirs at flume upstream and downstream were used. In this study, five-layer polyethylene pipes with three diameters of 20,25 and $32 \mathrm{~mm}$ were used to simulate rigid vegetation.

Two sliding valves at flume upstream and downstream are in charge of controlling the flow depth in the main channel and the discharge flow rate is set by the valves installed at the flume input and triangular spillway at flume downstream. Figure 1 presents the laboratory flume plan and Figure 2 shows a longitudinal view of the laboratory flume.

The experimental scenarios were determined based on 3 diameters, 2 discharge flow rates and 4 depths, as shown in Table 1.

Table 1 . The research variable parameters

\begin{tabular}{|l|c|}
\hline \multicolumn{1}{|c|}{ Variables } & Values \\
\hline $\mathrm{D}_{\mathrm{v}}(\mathrm{mm})$ & 20 25، 32 \\
\hline $\mathrm{Q}(\mathrm{Lit} / \mathrm{S})$ & $25 ، 30$ \\
\hline $\mathrm{y}(\mathrm{cm})$ & $10 \cdot 12$ ، $17 \cdot 20$ \\
\hline
\end{tabular}

Based on these values, 32 experiments (4 experiments in a rectangular channel without vegetation and 28 experiments in a rectangular channel with vegetation) were developed to examine the effect of each variable parameter on shear stress.

To measure the shear stress using a direct method, a device called a load cell and a special form of flume, i.e., knife edge flume, were used. The knife edge is made at $1 \mathrm{~m}$ from the flume length (control volume) in such a way that it is always to collapse and is balanced by the load cell and the embedded system. Hence, instead of collapsing, the resulting shear stress of the water flow is to be measured.

The knife edge section consists of eight $\mathrm{v}$-shaped backrests and 8 blades, which are in charge of unbalancing the concerned control volume. Figure 3 shows a schematic of the knife-edge section and how it is placed.

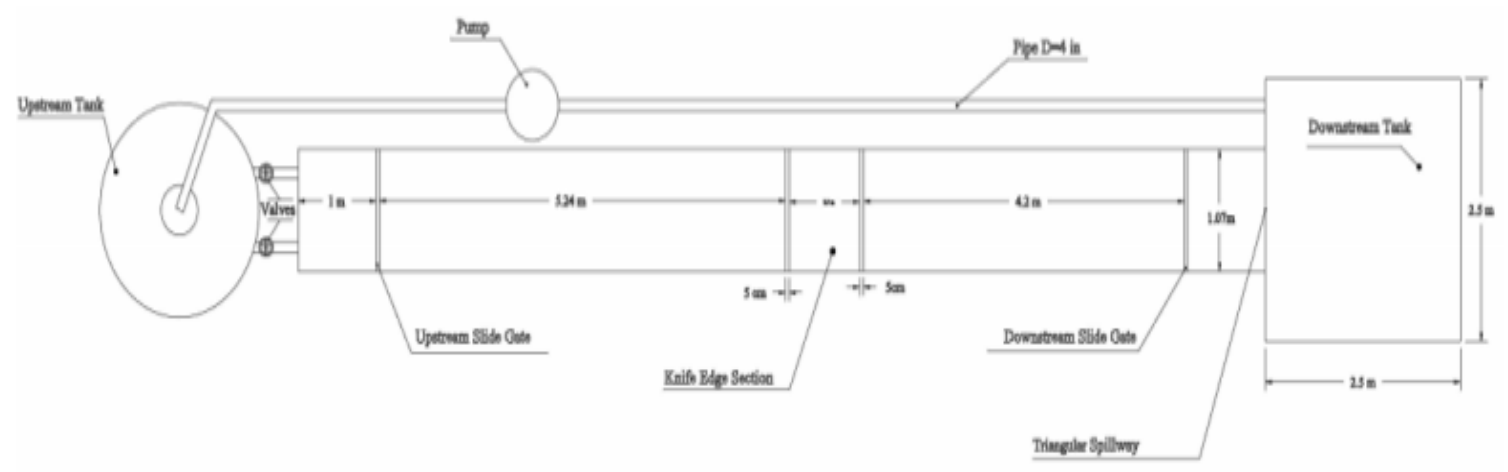

Figure 1. Laboratory Flume Plan 


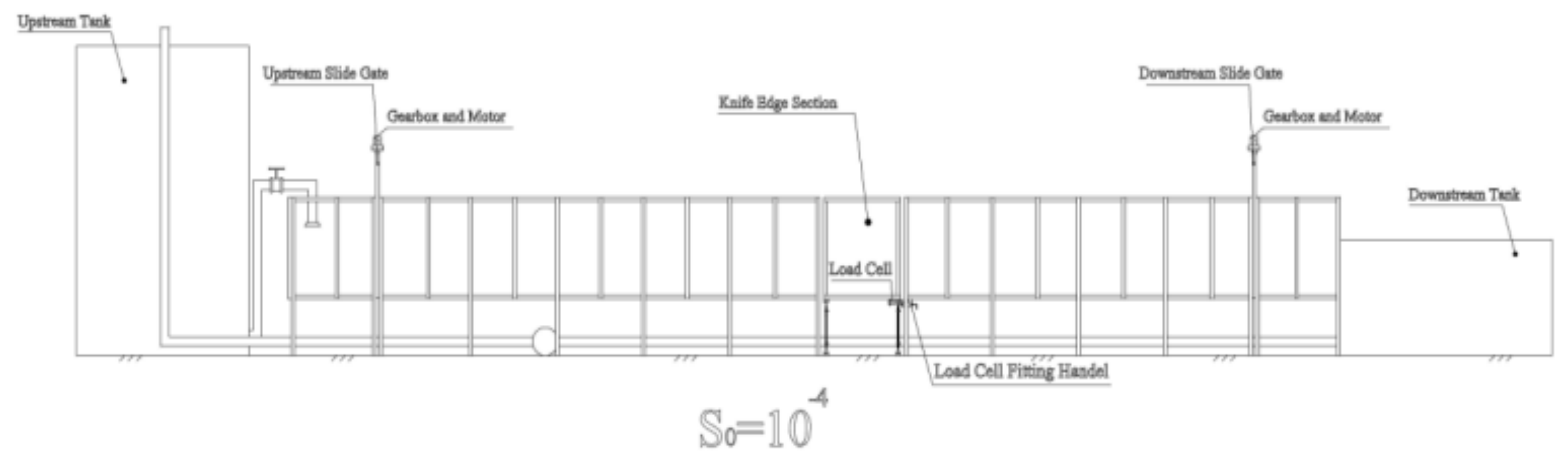

Figure 2. Longitudinal View of Laboratory Flume

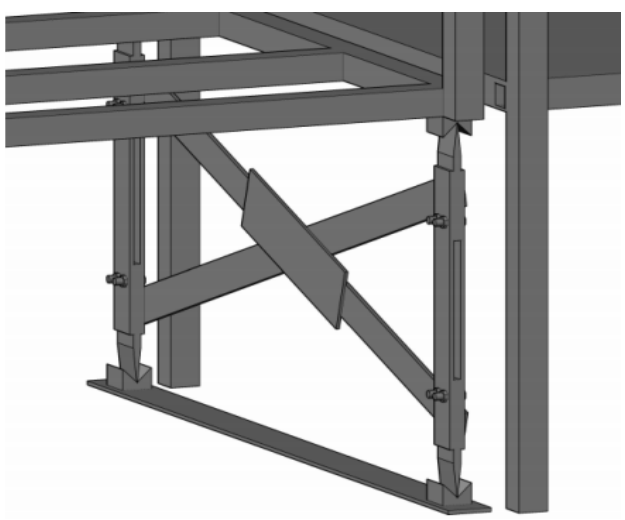

Figure 3. Schematic of Knife Edge

\section{RESULTS}

The results of the experiments are presented in the following diagrams. In these diagrams, the shear stress variations measured by the load cell are shown in terms of variations in vegetation diameter, depth, and flow discharge rates. In Figure 4 , all measured values are presented in different modes based on variations in flow depth.

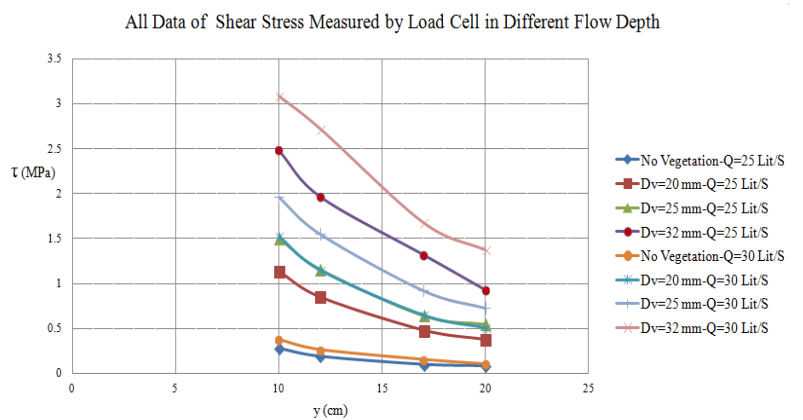

Figure 4. All Data of Shear Stress Measured by Load Cell in Different Flow Depths

In Figures 5 to 8 , the shear stress variation by vegetation diameters are presented in depths according to the tested flow discharge rates.

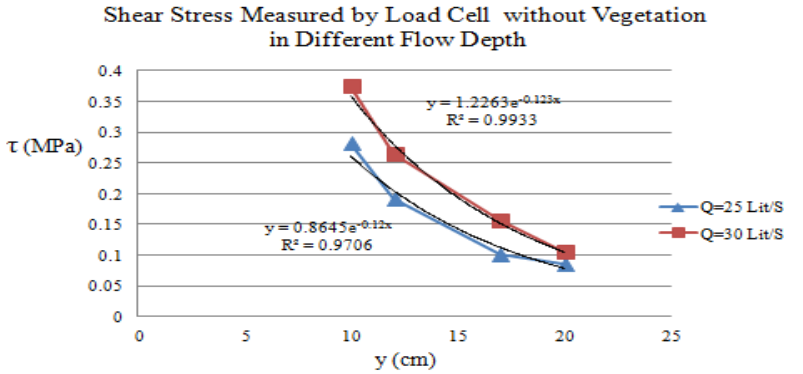

Figure 5. Shear Stress Measured by Load Cell without Vegetation at $\mathrm{Q}=25$ and $30 \mathrm{Lit} / \mathrm{S}$

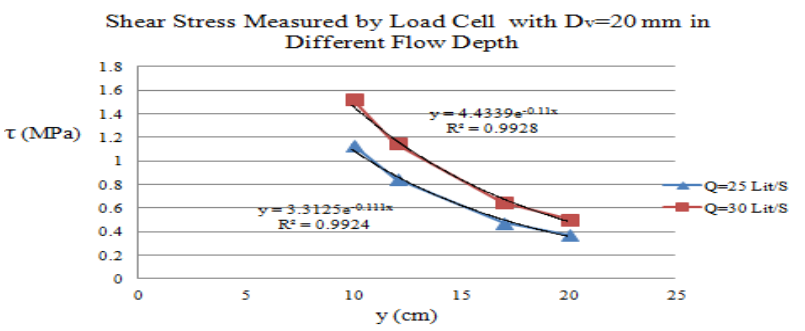

Figure 6. Shear Stress Measured by Load Cell with $D_{v}=20 \mathrm{~mm}$ at $\mathrm{Q}=25$ and $30 \mathrm{Lit} / \mathrm{S}$

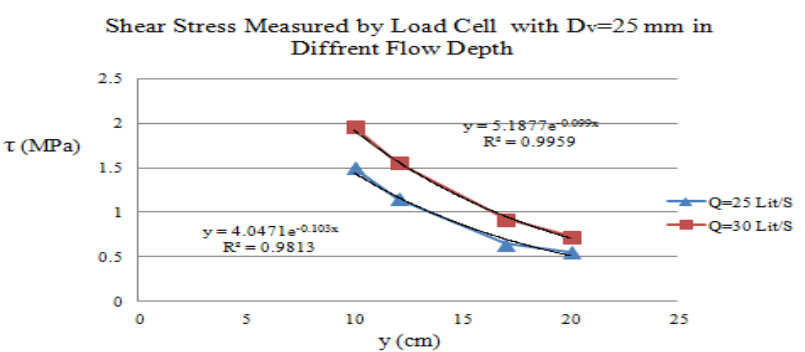

Figure 7. Shear Stress Measured by Load Cell with $D_{v}=25 \mathrm{~mm}$ at $\mathrm{Q}=25$ and $30 \mathrm{Lit} / \mathrm{S}$

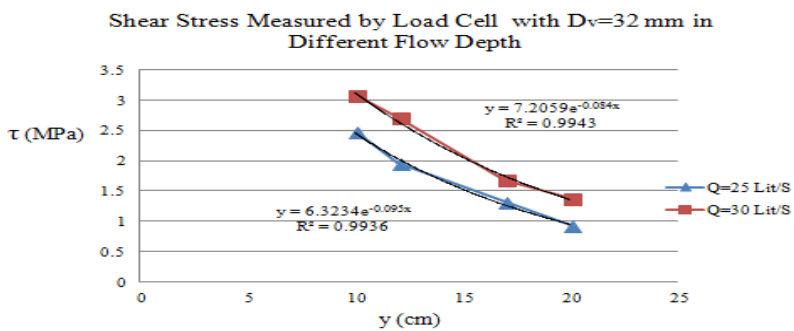

Figure 8. Shear Stress Measured by Load Cell with $D_{v}=32 \mathrm{~mm}$ at $\mathrm{Q}=25$ and $30 \mathrm{Lit} / \mathrm{S}$ 
Figures 9 to 12 shows shear stress variations by vegetation based on different depths and discharge rates.

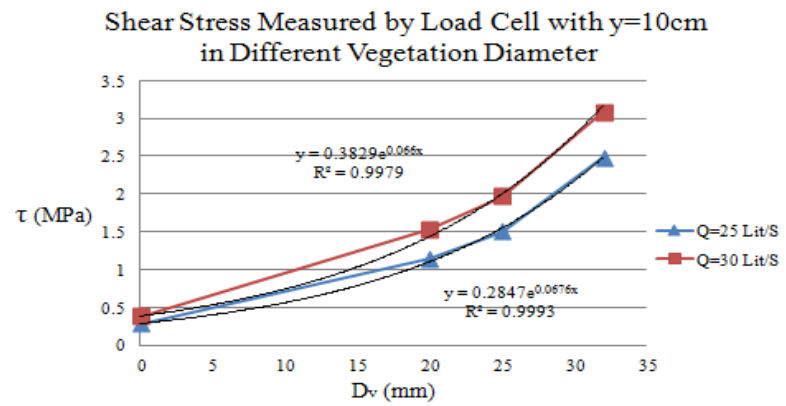

Figure 9. Shear Stress Measured by Load Cell with $y=10 \mathrm{~cm}$ at $\mathrm{Q}=25$ and $30 \mathrm{Lit} / \mathrm{S}$

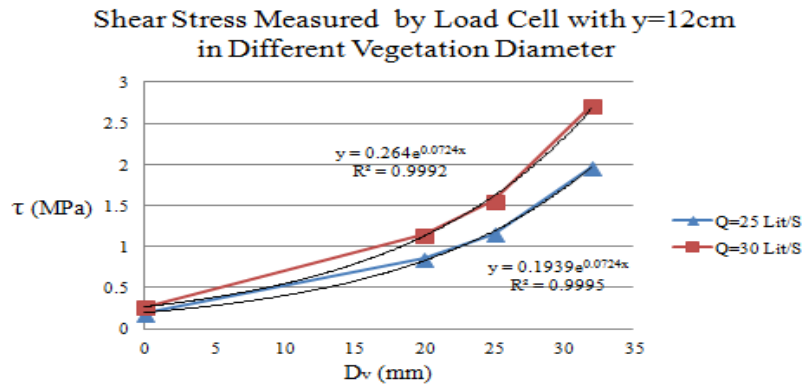

Figure 10. Shear Stress Measured by Load Cell with $y=12 \mathrm{~cm}$ at $\mathrm{Q}=25$ and $30 \mathrm{Lit} / \mathrm{S}$

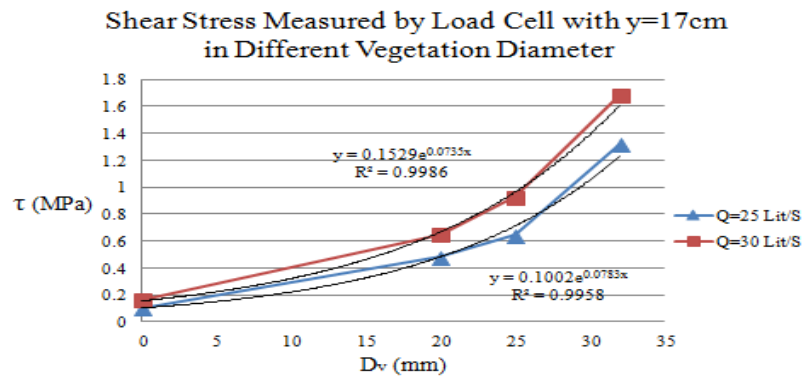

Figure 11. Shear Stress Measured by Load Cell with $y=17 \mathrm{~cm}$ at $\mathrm{Q}=25$ and $30 \mathrm{Lit} / \mathrm{S}$

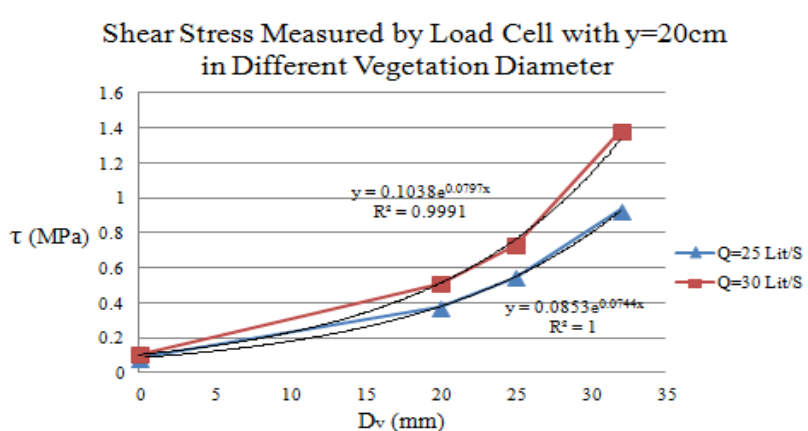

Figure 12. Shear Stress Measured by Load Cell with $\mathrm{y}=20 \mathrm{~cm}$ at $\mathrm{Q}=25$ and $30 \mathrm{Lit} / \mathrm{S}$

Figures 13 and 14 will shows the measured shear stress at discharge flow rates of 25 and $30 \mathrm{Lit} / \mathrm{S}$ according to the vegetation diameter variations.

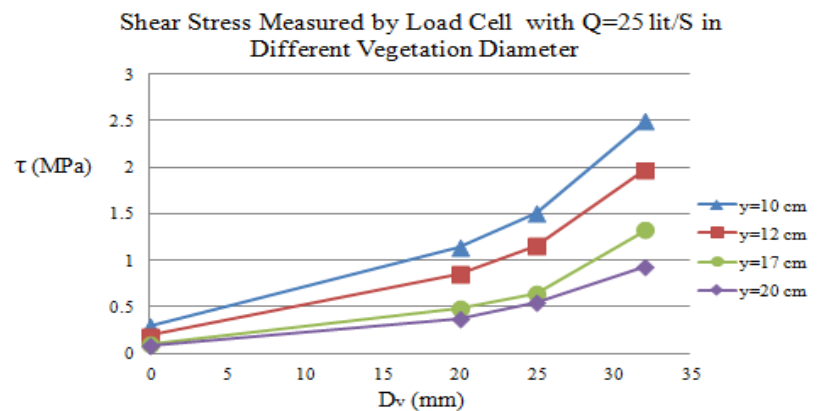

Figure 13. Shear Stress Measured by Flow depth with $\mathrm{Q}=25 \mathrm{Lit} / \mathrm{S}$ in Different Vegetation

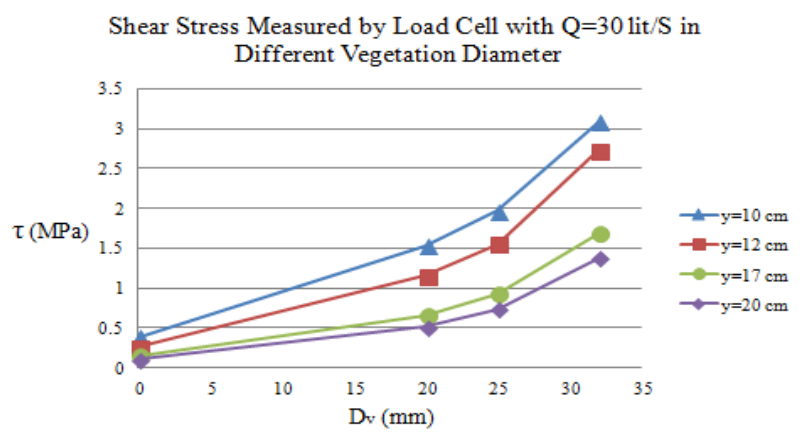

Figure 14. Shear Stress Measured by Flow depth with $\mathrm{Q}=30 \mathrm{Lit} / \mathrm{S}$ in Different Vegetation Diameter

In these diagrams, the shear stress values are distinguished based on the concerned depths, so that the simultaneous effect of the variation in vegetation diameter and flow depth is clearly demonstrated.

Figures 15 to 24 are presented in accordance with Figures 5-14 and the only difference is that the ratio of measured shear stress to calculated shear stress is concerned in the horizontal axis.

$$
\tau_{0}=\gamma R S_{0}
$$

Equation (2) shows how to calculate a computational shear stress. In this equation, $\tau_{o}$ is computational shear stress, $\gamma$ is fluid mass, $\boldsymbol{R}$ is hydraulic radius of the channel and $S_{0}$ stands for the channel bed slope.

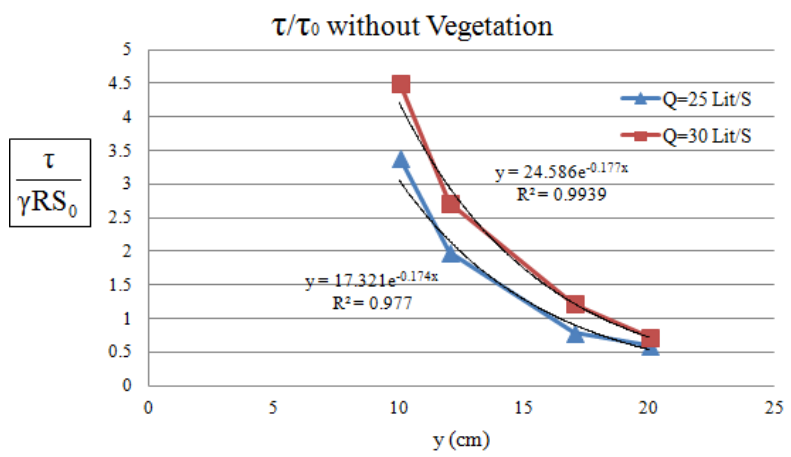

Figure 15. Ratio of Measured Shear Stress to Calculated Shear Stress by Flow Depth without Vegetation at $Q=25$ and $30 \mathrm{Lit} / \mathrm{S}$ 


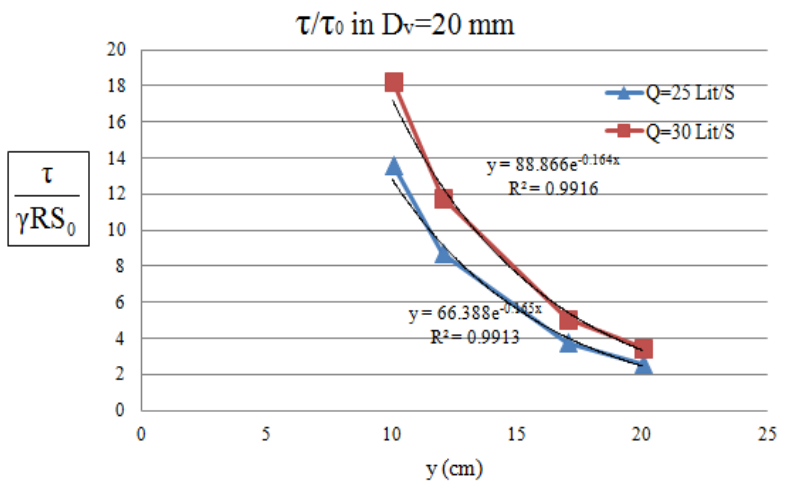

Figure 16. Ratio of Measured Shear Stress to Calculated Shear Stress by Flow Depth with $D_{v}=20 \mathrm{~mm}$ at $\mathrm{Q}=25$ and $30 \mathrm{Lit} / \mathrm{S}$

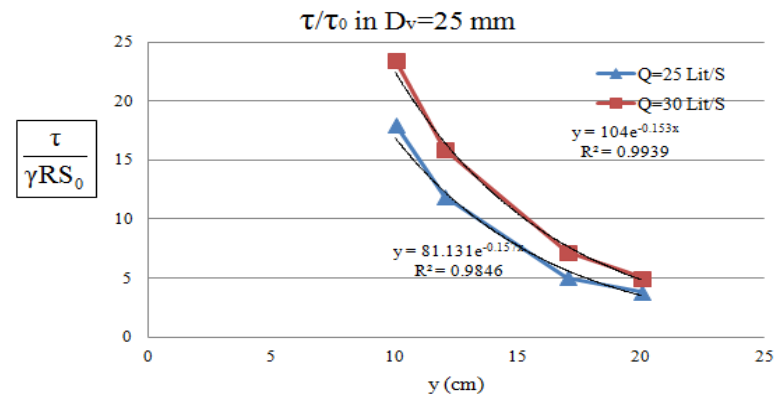

Figure 17. Ratio of Measured Shear Stress to Calculated Shear Stress by Flow Depth with $D_{v}=25 \mathrm{~mm}$ at $\mathrm{Q}=25$ and $30 \mathrm{Lit} / \mathrm{S}$

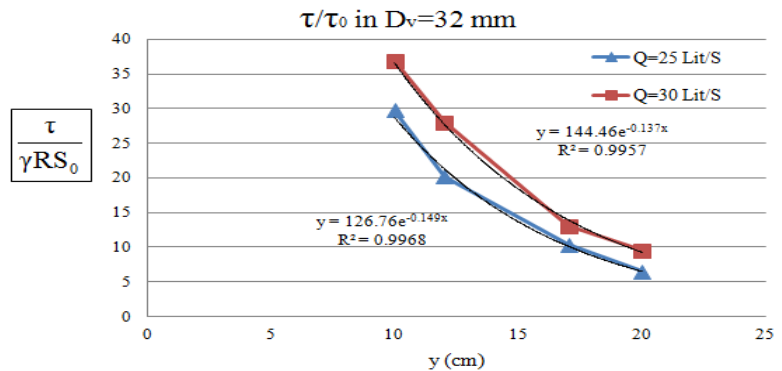

Figure 18. Ratio of Measured Shear Stress to Calculated Shear Stress by Flow Depth with $D_{v}=32 \mathrm{~mm}$ at $Q=25$ and $30 \mathrm{Lit} / \mathrm{S}$

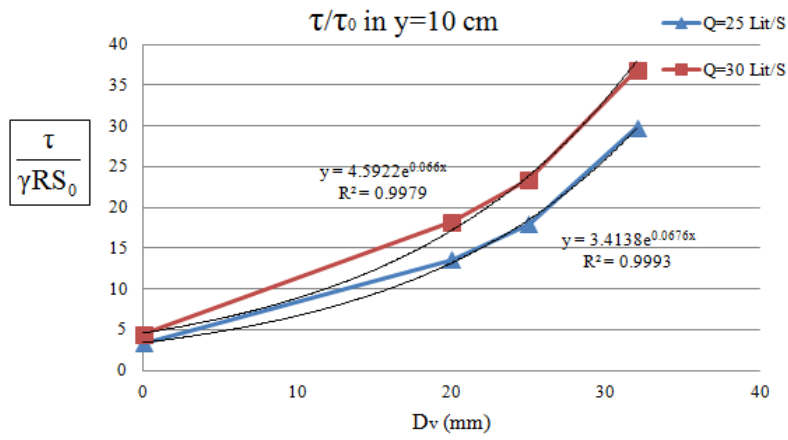

Figure 19. Ratio of Measured Shear Stress to Calculated Shear Stress by Vegetation Diameter with $\mathrm{y}=10 \mathrm{~cm}$ at $\mathrm{Q}=25$ and 30 Lit/S

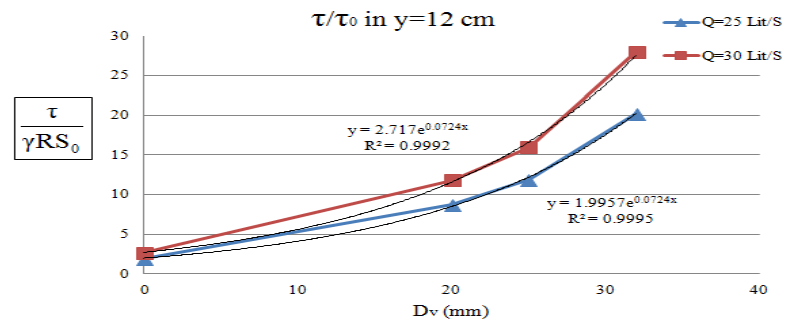

Figure 20. Ratio of Measured Shear Stress to Calculated Shear Stress by Vegetation Diameter with $\mathrm{y}=12 \mathrm{~cm}$ at $\mathrm{Q}=25$ and 30 $\mathrm{Lit} / \mathrm{S}$

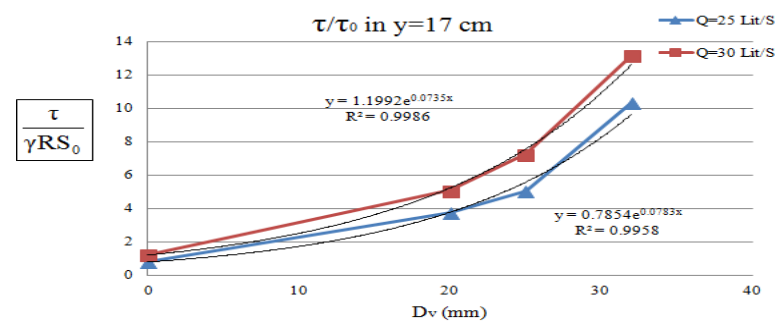

Figure 21. Ratio of Measured Shear Stress to Calculated Shear Stress by Vegetation Diameter with $\mathrm{y}=17 \mathrm{~cm}$ at $\mathrm{Q}=25$ and 30 Lit/S

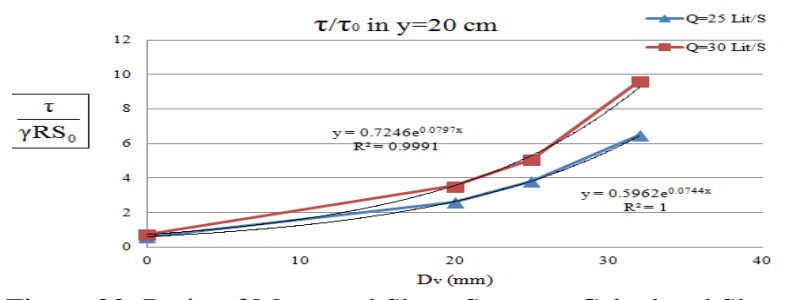

Figure 22. Ratio of Measured Shear Stress to Calculated Shear Stress by Vegetation Diameter with $\mathrm{y}=20 \mathrm{~cm}$ at $\mathrm{Q}=25$ and 30 Lit/S

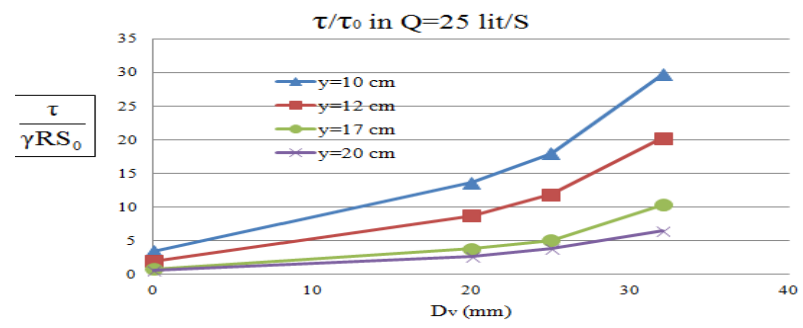

Figure 23. Ratio of Measured Shear Stress to Calculated Shear Stress in Different Vegetation Diameters by Flow Depth at $\mathrm{Q}=$ $25 \mathrm{Lit} / \mathrm{S}$

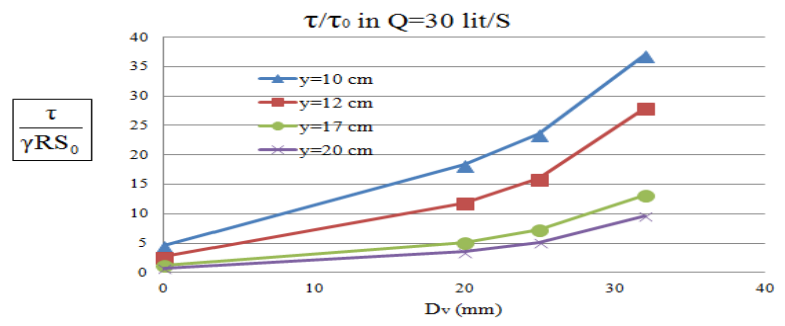

Figure 24. Ratio of Measured Shear Stress to Calculated Shear Stress in Different Vegetation Diameters by Flow Depth at $\mathrm{Q}=$ $30 \mathrm{Lit} / \mathrm{S}$ 
In Fig. 25, the laboratory data obtained from measured shear stress to calculated shear stress according to $\mathrm{D}_{\mathrm{V}} / \mathrm{y}$ are represented.

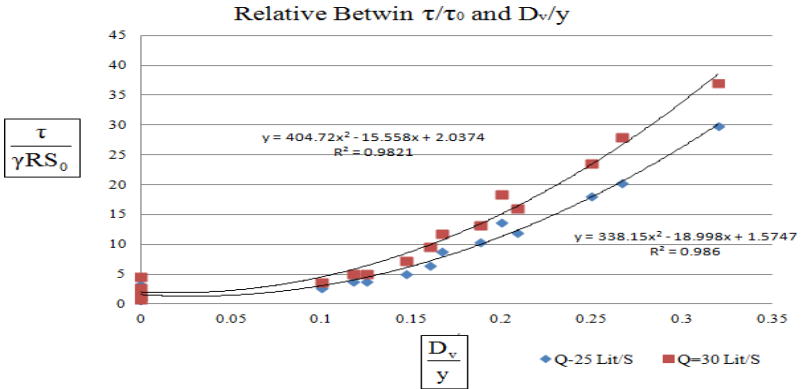

Figure 25. Ratio of Measured Shear Stress to Calculated Shear Stress according to $\mathrm{D}_{\mathrm{V}} / \mathrm{y}$ at $\mathrm{Q}=25$ and $30 \mathrm{Lit} / \mathrm{S}$

In all figures, except Figures 4, 14, 15, 23 and 24, the data trend lines are presented. According to the correlation coefficients $\left(\mathrm{R}^{2}\right)$, these equations are of an acceptable accuracy. In all figure with trend lines but Figure 25, the line equation of exponential function was used to enhance the correlation coefficient. In Figure 25, a power line function was used to present the trend lines of the dimensionless graph. Trend line equations can be used as a computational equation for obtaining shear stress in the range concerned in each graph.

A review of the diagrams suggested that the measured shear stress increases with enhancing the diameter in the channel in different discharge flows rates and depths. This is evident in Figures 9 to 11 . According to Figures 5 to 8 , the shear stress decreases at a constant flow discharge rate with increasing flow depth. This can be described with respect to the average velocity decrease in the channel.

In Figures 15 to 18 , which indicates variations in $\frac{\tau_{0}}{\tau}$ in terms of the flow depth, it was observed that the value of the dimensionless parameter $\frac{\tau_{\phi}}{\tau}$, such as the shear stress measured by the load cell, decreases with increasing depth in the constant flow discharge rate. This dimensionless ratio in Figures 19 to 22 is increased with increasing vegetation diameter.

In Figure 25, all measured data were placed with $\mathrm{Q}=25$ and 30 $\mathrm{Lit} / \mathrm{S}$ in a graph with two dimensional axes indicating the variations of $\frac{\tau_{0}}{\tau}$ to $\frac{D_{V}}{y}$ and the trend lines were plotted for each of the flow discharge rates. This figure shows $\frac{\tau_{0}}{\tau}$ ratio increases with increasing the $\frac{D_{v}}{y}$ in both flow discharge rates. The value was greater in $\mathrm{Q}=30 \mathrm{Lit} / \mathrm{S}$ than $\mathrm{Q}=25 \mathrm{Lit} / \mathrm{S}$.

\section{DISCUSSION AND CONCLUSIONS}

Based on the results obtained from 32 physical models simulated in a hydraulic knife edge flume, in which the shear stress measurements were performed using load cell, it can be concluded that:
In a constant discharge flow, the shear stress and the $\frac{\mathbf{T}_{0}}{\tau}$ ratio decrease as the flow depth increases. This might be due to a decrease of average velocity in the channel.

2. Increasing the vegetation diameter increases the shear stress $\underline{z_{0}}$

and $\bar{\tau}$ ratio due to enhancing the vegetation density against the flow.

With regard to the trend lines in Figure 25, the following equations can be formulated for $\mathrm{Q}=25$ and $30 \mathrm{Lit} / \mathrm{S}$, a uniform vegetation diameter and regular arrangements:

$Q=25 \frac{L i t}{S} \rightarrow \frac{\tau}{\gamma R S_{0}}=358.15\left(\frac{D_{v}}{y}\right)^{2}-18.998\left(\frac{D_{v}}{y}\right)+. .5747$
$Q=30 \frac{\mathrm{Lit}}{\mathrm{S}} \rightarrow \frac{\tau}{\gamma R S_{0}}=404.72\left(\frac{D_{v}}{y}\right)^{2}-15.588\left(\frac{D_{v}}{y}\right)+2.0974$

\section{References:}

Hoshmandi F., Zahiri A., Dehghani A. A. and Meftah Halghi M., 2014, "Comparison of Estimation of Shear Stress Distribution in Open Channels", Journal of Soil and Water Protection Research, 21(5), 284-295.

I. Nezu, and H. Nakagawa, 1993, "Turbulence in open-channel flows", Rotterdam, The Netherlands: Balkema.

D. W. Knight, J. D. Demetrious, and M. E. Hamed, 1984, "Boundary shear in smooth rectangular channel", J. Hydraulic Eng., 110(4), 405- 422.

A. Tominaga, I., Nezu, K. Ezaki, and H. Nakagawa, 1989, "Threedimensional turbulent structure in straight open channel flows", Journal of Hydraulic Research, 27, 149-173.

S. Dey, and M. F. Lambert, 2005, "Reynolds and bed shear in nonuniform unsteady open-channel flow", Journal of. Hydraulic Engineering, 131(7), 610-614.

J. Guo, and P. Y. Julien, 2005, "Shear stress in smooth rectangular open channel flows", Journal of. Hydraulic Engineering, 131, 30-37.

A. R Zarrati., Y. C. Jin, and S. Karimpour, 2008, "Semianalytical model for shear stress distribution in simple and compound open channel flows", Journal of. Hydraulic Engineering, 134(2), 187-192.

Behdarvandi Askar M., Fathi Moghadam M. and Mosavi Jahromi S. H., 2013, "Comparison of the method of energy and the size of motion in the investigation of the transfer of the size of movement between the sub sections of a compound cross section", Journal of Water Resources Engineering, $6^{\text {th }}$ year, Summer, 1-14. 